\title{
Preparing Aerospace Engineering Students for Career in UAV Technologies
}

\section{Dr. Subodh Bhandari, Cal Poly Pomona}

Dr. Bhandari is a professor in the Department of Aerospace Engineering at Cal Poly Pomona. He received his PhD from University of Kansas in 2007. His expertise is in the area of Aircraft Dynamics and Control and Unmanned Systems. He has been actively involved in training a future generation of engineers in the area of unmanned vehicles system. His current research emphasis is on increased autonomy of unmanned aerial vehicles (UAVs), UAV-unmanned ground vehicle collaboration, robust and intelligent control, collision and obstacle avoidance system for UASs, and developing capabilities for widespread use of unmanned vehicles. Dr. Bhandari leads a multi-disciplinary team of faculty and students from several departments within the Colleges of Engineering and Science at Cal Poly Pomona for research on unmanned systems. He has obtained federal and industry support for his research on unmanned systems, and has published several papers on his research. He is a senior member of American Institute of Aeronautics and Astronautics (AIAA) and a member of American Helicopter Society (AHS), Association for Unmanned Vehicles International (AUVSI), and American Society of Engineering Education (ASEE). 


\title{
Preparing Aerospace Engineering Students for Career in UAV Technologies
}

\begin{abstract}
Unmanned Aerial Vehicles (UAVs) have potential of reducing human casualty and cost for many dull, dirty, and dangerous missions. UAVs are one of the fastest growing sectors of Aerospace Industry. However, there is a lack of professionals entering the workforce. There is also a lack of students pursuing studies for graduate degrees in the UAV related areas. This paper talks about innovative projects and teaching practices designed to increase students' interest and involvement in UAV related projects. Many aspects of UAV technologies are not or cannot usually be taught in classroom settings. Student and/or research projects are effective ways of exposing students to the state-of-the-art in UAV technologies. These projects provide students opportunity to learn new skills and apply their knowledge to the real-world problems in an environment that includes students from multiple departments. The students get ample opportunity to develop theoretical understanding, by means of hands-on learning, and apply the knowledge to designing, building, performing system integration, modeling, simulation, and flight testing of UAVs. The students also get opportunities for data collection and data analysis.

An assessment of the learning outcomes showed that these projects were helpful in well preparing the students for careers in UAV technologies. These projects have also been found to be effective in encouraging students to pursue their studies for graduate degrees in the area of UAV technologies. Involvement in these projects motivates students to effectively engage in learning and develop new understanding, knowledge, and skills. The paper also describes the strategies to recruit and train lower level students for the continued involvement of students in these projects.
\end{abstract}

\section{Introduction}

UAVs have potential to replace manned aircraft for many applications such as intelligence, surveillance, and reconnaissance (ISR), remote sensing, search and rescue missions, border patrol, surveillance of disaster-hit areas, aerial photography, aerial mapping for geotechnical survey, vegetation growth analysis, crop dusting, precision agriculture, assessment of topographical changes, power line inspection, etc.

The UAV industry is the fastest growing sector of the aerospace industries and the use of UAVs has been growing significantly for civilian applications ${ }^{1}$. It is estimated that UAV spending in the US will be more than $\$ 90$ billion over the next decade, and that will not only create tens of thousands of jobs, but also save money for federal, state, and local governments and taxpayers by dramatically reducing the need for expensive manned airplanes and helicopters for a number of missions.

Though the role of UAVs in the US and worldwide economy is increasing, there is a lack of professionals entering the workforce for UAV-related jobs. Many students may not yet be aware of the existence of UAVs or their importance to our society. Ongoing projects at Cal Poly 
Pomona are designed to expose the students to the state-of-the-art in UAV technologies, and well prepare them for future assignments in industry and academia, especially in the area of UAV technologies.

The Department of Aerospace Engineering at Cal Poly Pomona is currently engaged in several UAV research projects. Current research focus is on increasing the UAV autonomy. The ongoing research projects include autonomous operation, development and validation of flight dynamics models of $\mathrm{UAVs}^{2}$, modeling and simulation, development of obstacle and collision avoidance capabilities ${ }^{3,4,5}$, collaboration between unmanned aerial and ground vehicles, ${ }^{6}$ tracking of mobile targets using UAVs, ${ }^{7}$ vegetation growth analysis using UAVs, ${ }^{8}$ and environmental gas monitoring using UAVs. These projects involve faculty and students from several departments within the Colleges of Engineering and Science including Aerospace Engineering, Electrical \& Computer Engineering, and Computer Science departments.

An excellent collection of UAVs and associated equipment at the university facilitates these projects. The UAV Lab at Cal Poly Pomona has more than fifteen fixed- and rotary-wing UAVs

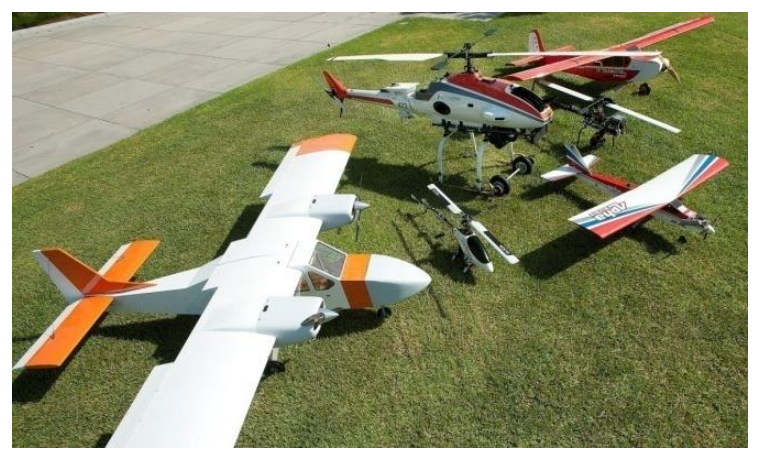

Figure 1: UAV Fleet of various sizes and payload capacities. Some of the UAVs are shown in Figure 1. Also available for the projects are autopilots, inertial measurement units (IMUs), differential GPS, stabilized camera gimbal, multispectral and infrared cameras, LIDAR, etc. The UAV Lab provides facilities, tools, equipment, and guidance for individuals and teams from throughout the university. Cooperation between different disciplines is encouraged. The UAV Lab is an ideal, low-cost means for the students to gain "real-life" engineering experience with meaningful projects. Students may suggest their own project concepts, or they may work on sponsored project concepts funded by industry or government agencies.

The students work on these projects as part of their mandatory senior project, as research assistants, independent study, or as volunteers. The projects are designed to educate aerospace engineering students, by means of hands-on learning and by involving them in projects related to the real-world applications, many advanced topics in the areas of flight dynamics and control, artificial intelligence, computer vision, UAV autonomy, collision and obstacle avoidance, avionics systems, and other topics. The projects give students an opportunity to design, analyze, build, integrate, and test unmanned aerial systems, both in simulation and flights. The projects also give students experience working with faculty member(s) and help well prepare them in their oral and written communication skills. Lack of strong written and oral communications has been identified as deficiency in STEM education, resulting in poor success rate. The students from several departments including Aerospace Engineering, Electrical \& Computer Engineering, and Computer Science Departments work on these projects in an interdisciplinary environment. The goal is to involve the students in these projects for an extended period of time, starting with the freshman or sophomore year until their graduation. Research shows an extended participation in projects and research results in an increase in the students' GPAs and their overall success ${ }^{9}$. 
These project have given a large number of students opportunities to apply the knowledge learned in class rooms as well as the newly acquired skills to real-world problems, usually for an extended period of time or throughout their educational career at Cal Poly Pomona. Figure 2 shows the number of students involved in these projects for the past five years. It can be seen that the number of students involved in these projects is increasing over time. Again, the goal is to prepare a strong workforce for the future needs of industry and academia. The projects that students work on represent the problems that aerospace industry in general and UAV industry in particular is currently involved in, and generally involve advanced topics that are relevant to the state-of-the art. The students get ample opportunities in identifying, formulating, and solving engineering problems related to UAV technologies. The students also get opportunities to designing experiments for flight tests as well as collecting and analyzing flight data. The data is then used, for example, in validating the developed flight dynamics models similar to what is practiced in the industry.

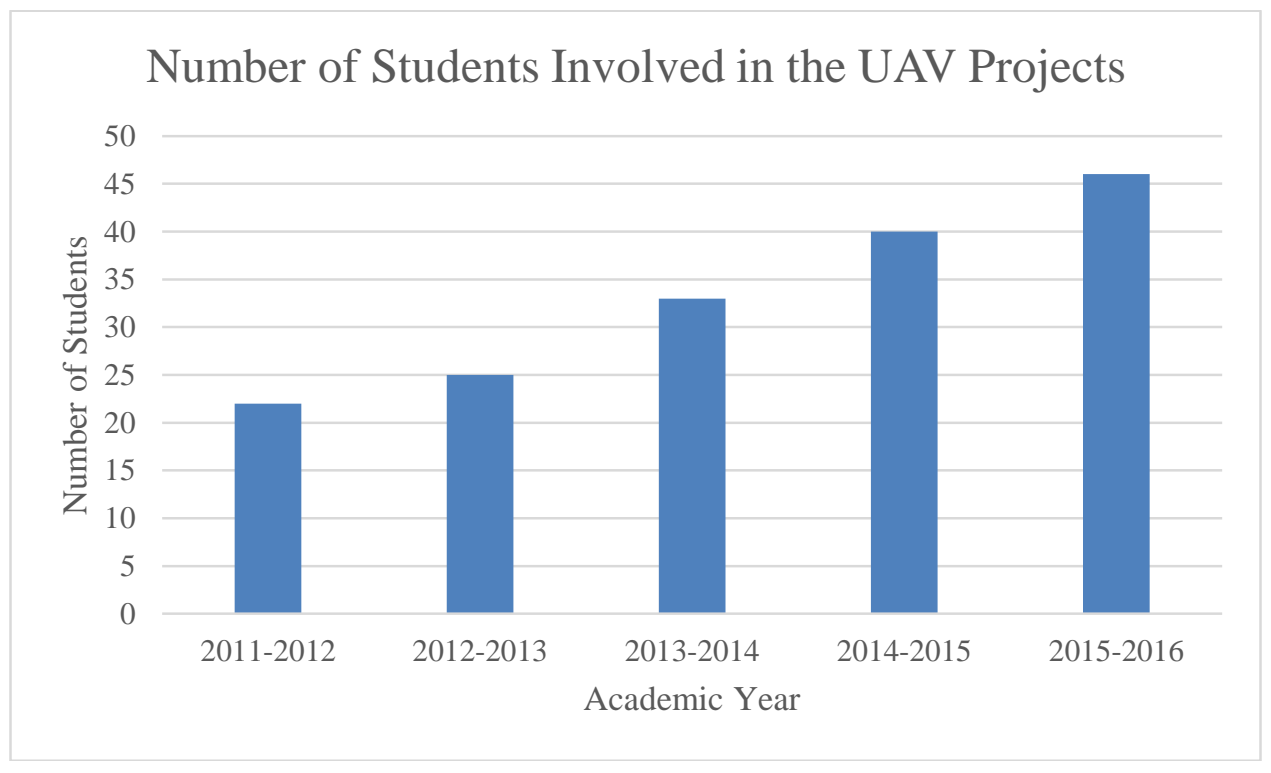

Figure 2: Number of Students Involved in UAV Projects

The rest of the paper is organized as follows. Section II presents some sample projects that students are involved in. Assessment of student success is presented in Section III. Section IV presents the administration of the projects followed by the conclusion in the last section.

\section{Sample Projects}

Projects in UAV technologies are designed to expose students to state-of-the-art in UAV technologies, and thoroughly prepare them for career in industry and academia. The goal is to encourage students and give an opportunity to all the interested students to get involved in these projects. The following paragraphs describe some of the projects that the students are being involved in.

\section{A. UAV Autonomous Operation}


For autonomous operation, the students have been using commercial-off-the-shelf autopilots such as Piccolo autopilot, Micropilot, and Ardupilot. The students have also been working on developing custom autopilots ${ }^{10}$. Figure 3 shows an example mission planner and ground control station for autonomous operation. Students from Aerospace Engineering, Electrical \& Computer Engineering, and Computer Science Departments work together for autonomous operation of UAVs.

A group of students from these three Departments participate in the Association for Unmanned Vehicles Systems International's (AUVSI) Student Unmanned Aerial System (SUAS)

Competition every year. The competition involves autonomous operation of UAVs. The students also work on other aspects of the competition such as target recognition, obstacle avoidance, and autonomous payload release.

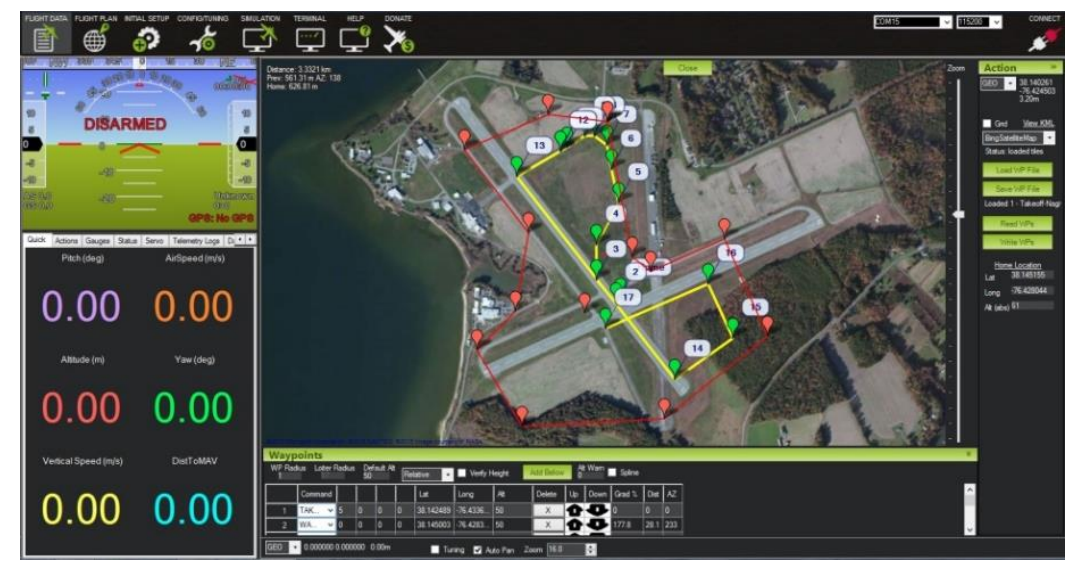

Figure 3: Mission Planner for Autonomous Operation

Figure 4 shows a Sig Kadet Senior UAV being used by students for various autonomous projects including search and rescue missions. The students are seen preparing the UAV for flight tests.

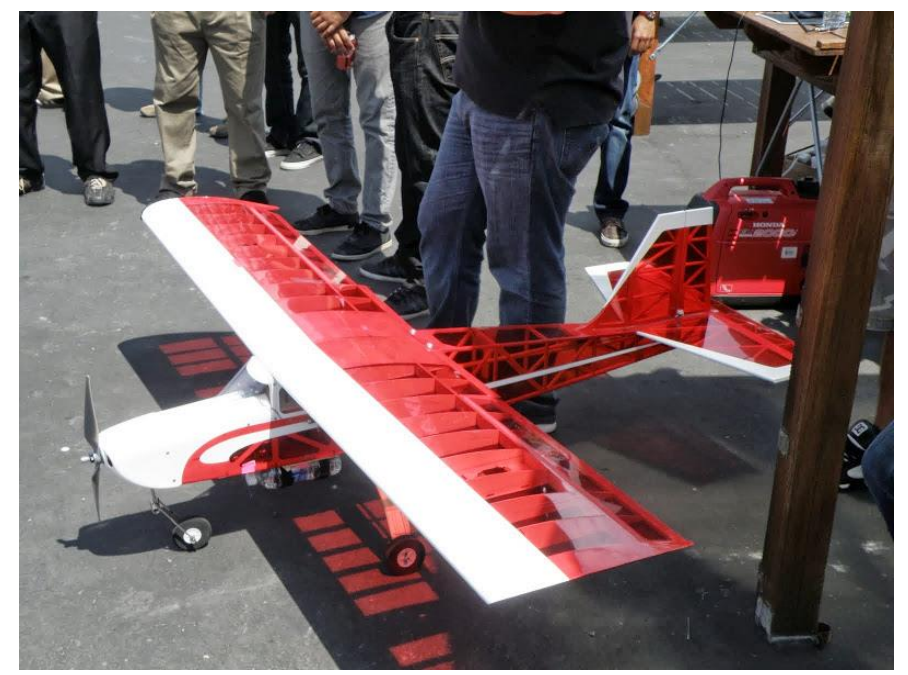

Figure 4: Sig Kadet Senior UAV

\section{B. Modeling and Simulation}


Prior to testing the vehicles in flight, the students use modeling and simulation software tools to analyze the performance of the vehicles including flight dynamics analysis. The stability and control derivatives required for flight dynamic analysis are usually obtained using Athena Vortex Lattice (AVL) or other software, and are validated using flight data ${ }^{2}$. Figure 5 shows the model of the Sig Kadet UAV in the AVL software.

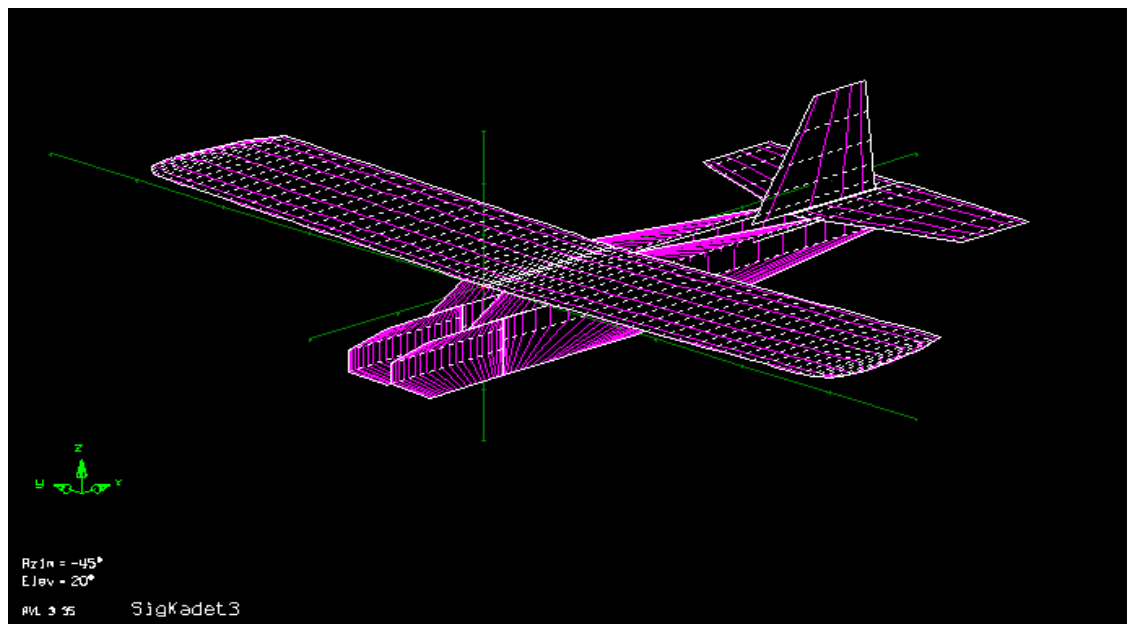

Figure 5. Sig Kadet Geometric Model in AVL

The validated flight dynamics model is then used in software-in-the-loop (SIL) and hardware-inthe-loop (HIL) simulation environments. These simulations greatly reduce both the time required for testing as well as reduce the development time by facilitating debugging and troubleshooting. These simulations use FlightGear Flight Simulator. Figure 6 shows the UAV in FlightGear simulation, which is used for both SIL and HIL simulations ${ }^{2}$. Both open-loop and autonomous flight can be visualized in FlightGear Simulator.

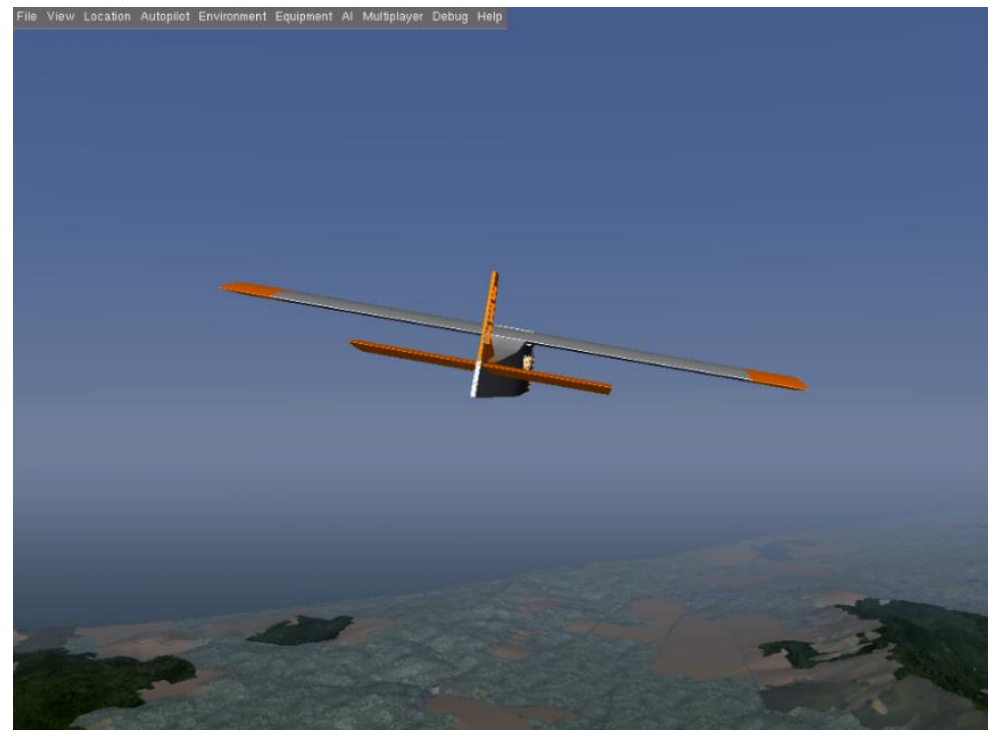

Figure 6: Visualization of Simulated Flight in FlightGear Simulator 


\section{Target Identification and Tracking}

An interdisciplinary team of students including Aerospace Engineering students work together to develop a UAV-based imaging systems for the identification and tracking of targets on the ground. The imaging system onboard the UAVs are used to identify the shape, size, color, and geographical locations of the targets ${ }^{7,11}$. Figure 7 shows an example of a target identified from the aerial image. The images are taken while the UAV flies autonomously over the target search area.

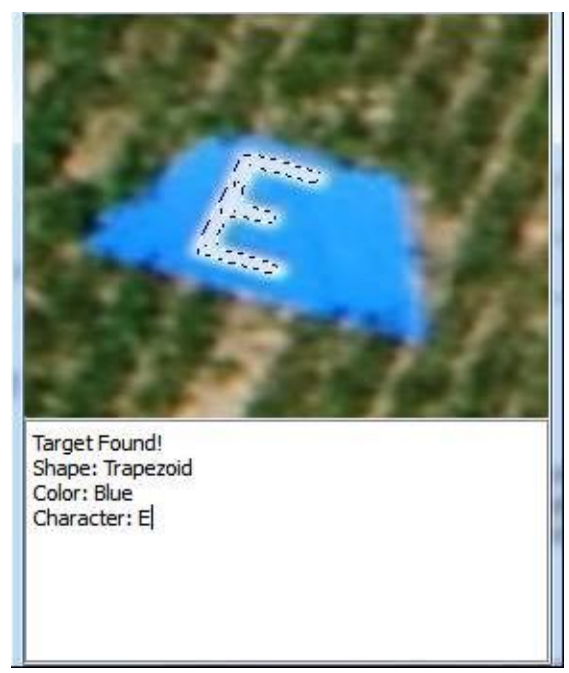

Figure 6: Target Recognition

For target tracking, the UAV was flown over the vehicle, and the vehicle was successfully detected by the imaging system in the UAV. The target location was also successfully sent from the tracking algorithm for the waypoint generation, which is based on knowing the location of the aircraft, the location of the target vehicle, and the angle between the target vehicle and a North-pointing vector. Because the camera and gimbal system are designed to always point in the nadir direction, the first assumption used is that the aircraft's location is always at the center of the camera's field of view. Next, using OpenCV libraries, the computer program is able to detect the target vehicle, as well as its $\mathrm{x}$ and $\mathrm{y}$ coordinates where $\mathrm{x}$ and $\mathrm{y}$ representing a number of pixels from the center of the field of view as shown in Figure 7 below. 


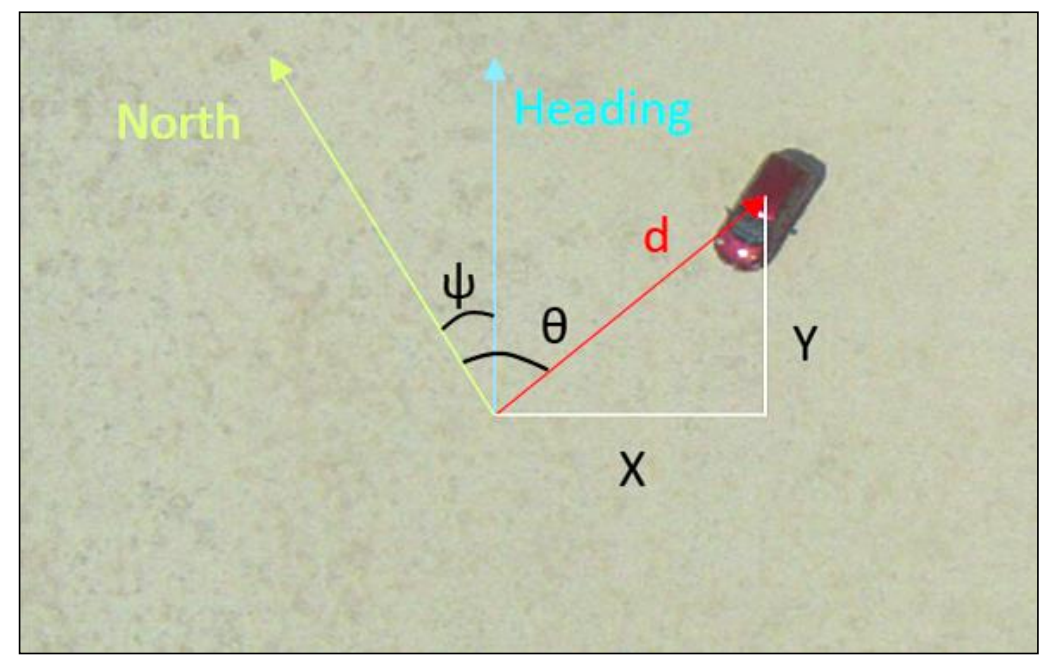

Figure 7. Coordinate System

Figure 8 below shows the distance vector between the aircraft and the vehicle along its component vectors and angle between them. In the figure, $\alpha$ is the total angle between the aircraft and the target vehicle in either the $\mathrm{x}$ or the $\mathrm{y}$ direction based on the number of pixels in either the $\mathrm{x}$ or the $\mathrm{y}$ direction.

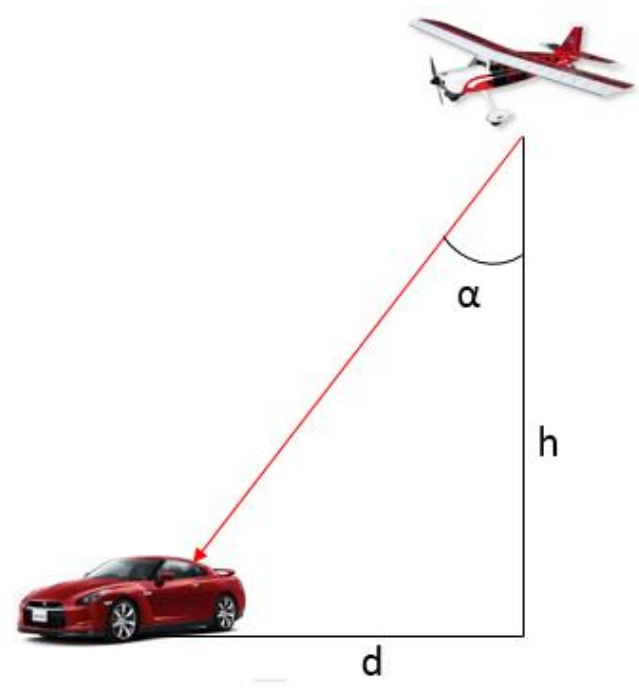

Figure 8: Aircraft-Target Position Vector

\section{UAV Collision and Obstacle Avoidance System}

In order to utilize the full potential of UAVs, they must be integrated into the National Airspace System (NAS). This requires that the UAVs must be capable of sensing and avoiding obstacles or other aircraft in their flight path ${ }^{12,13}$.

The collision avoidance system must be able to detect obstacles or other aircraft well ahead of collision, perform collision avoidance maneuver, and plan an alternate path for the continuation 
of the mission. For obstacle detection, sensors such as ADS-B transponders, laser scanners, camera, and sonars are being used ${ }^{3,4,5}$. The students have developed and implemented collision and obstacle avoidance algorithms and have tested them in simulation and flight tests for fixedwing UAVs as well as multicopters.

Students from Aerospace Engineering, Electrical \& Computer Engineering, and Computer Science Departments work together on developing collision and obstacle avoidance capabilities for the UAVs. Figures 9 shows the collision avoidance system being tested in a simulation environment for fixed-wing UAVs ${ }^{14}$.

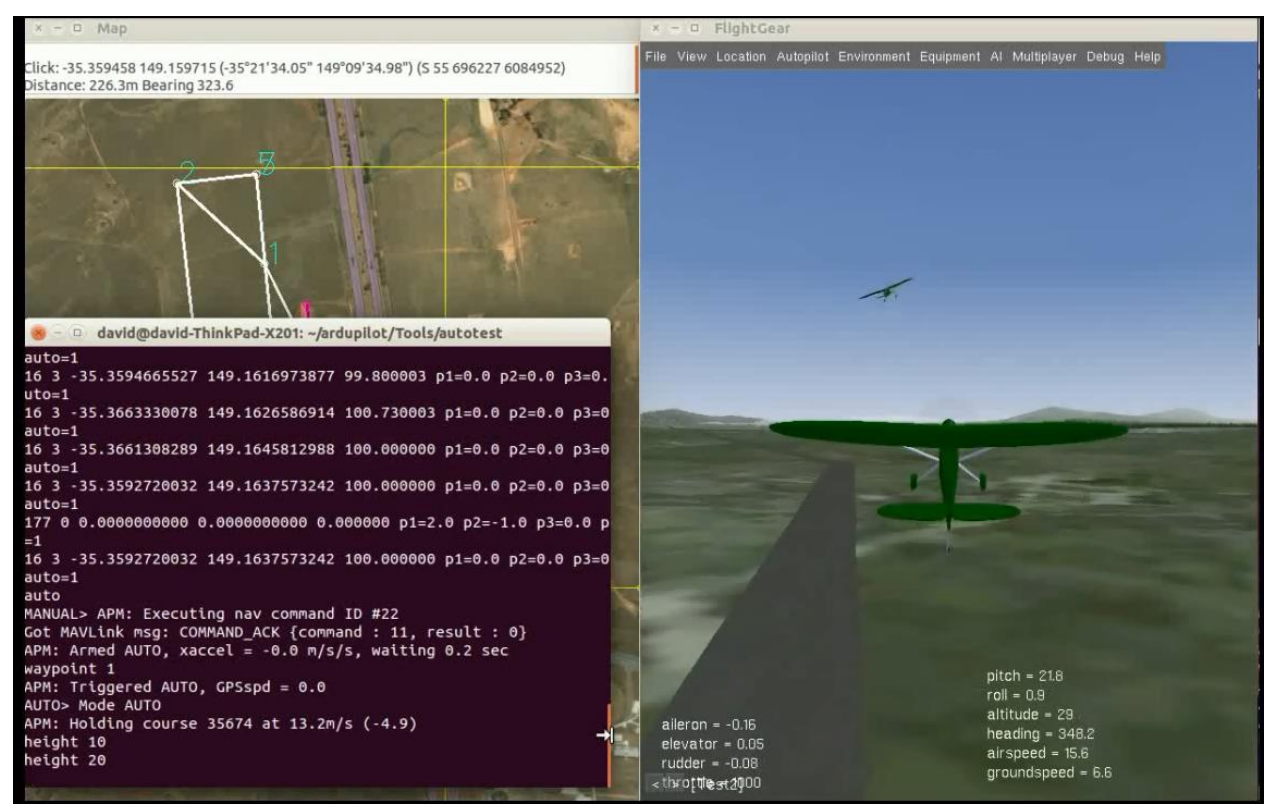

Figure 9: Software-in-the-Loop Simulation Interface for Collision Avoidance

Figure 10 shows a quadrotor being used for research on path planning and obstacle avoidance in an indoor environment ${ }^{15,16}$. The quadrotor is equipped with sonars as shown in the figure for obstacle detection and autopilot for autonomous navigation in the GPS-denied environment. 


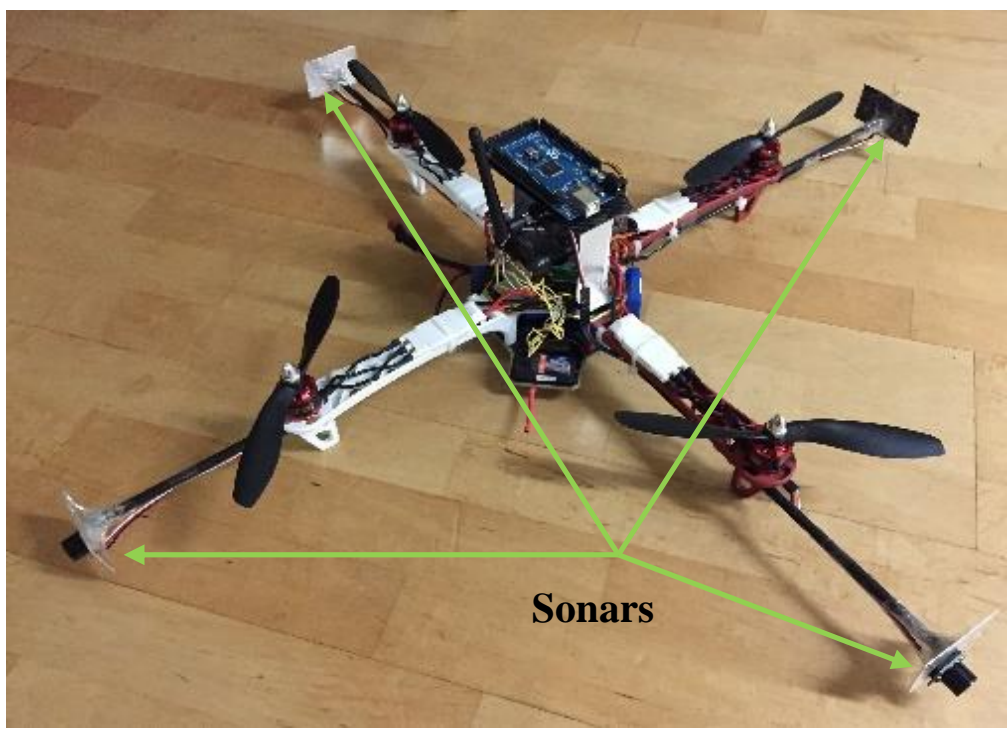

Figure 10: Quadrotor UAV being used for Obstacle Avoidance Project

Figure 11 shows the quadrotor traversing a collision free path in simulation.

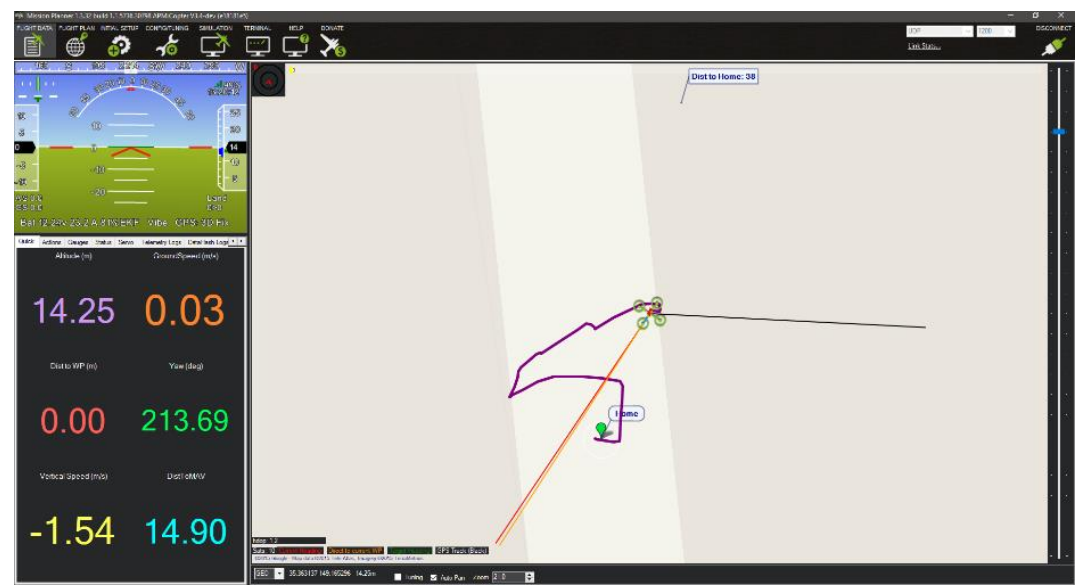

Figure 11: SIL Simulation Showing the Quadrotor Executing a Collision Free Path

\section{III.Administration of the Projects}

As mentioned above, the students work on these project as part of their Senior Projects, as research assistants or independent study, or as volunteers. The students working on the UAV projects work closely with the faculty supervisor (s) to meet the goals and objectives of the projects. The projects usually address or try to address the problems that the UAV operations is currently facing such as integration of the UAVs into the National Airspace System, Collision and Obstacle Avoidance, and Navigation in GPS-Denied Environments. They are asked to do literature review, and come up with a solution for problems that need further development and maturation. The students are highly encouraged to present their work during student and professional conferences. All this provides an intensive research environment where the students learn, by means of hands-on learning, state-of-the-art in UAV technologies. 
Every effort is made to involve students in these projects for an extended period of time rather than for only one academic year. Various recruiting strategies are adopted in order to make sure that the lower level students are aware of the ongoing projects and that they are encouraged to participate in these projects. The students currently involved in these projects are a great source for recruiting new students through the word of mouth. The outreach activities are also helpful in recruiting the students. The student currently involved in these projects are asked to present the work being done during student club meetings such as AIAA Student Branch meetings. The students are also recruited by faculty members.

\section{IV.Assessment of Student Success}

The student involvement in the projects described above and other projects on unmanned aerial systems has been found to be very effective in preparing them for career in UAV technologies and/or graduate studies. These projects have also been found to be very effective in enhancing student learning experience. Some of the key findings are presented in the following paragraphs.

\section{A. Increased Preparedness for Industry Career}

The students involved in these projects have shown increased preparedness for the industry career, mostly related to UAV technologies. Many students involved in the projects have been successful in getting employed immediately after the graduation in the areas of UAV technologies and computer science.

Figure 2 in Section I shows the number of students involved in the UAV projects in the past five years. Over $60 \%$ of the graduated students who were part of the projects have been hired by companies that are involved in UAV technologies. Approximately 50 students who graduated within last five years have directly been working in the areas of UAV technologies and related areas. The number is based on the information provided by the students or the information gathered from the methods used for student tracking. Various methods have been used to track the students after graduation such as E-mail, Facebook, and LinkedIn. These methods are also valuable in measuring their success in industry and academia such as promotion, completion of advanced degrees, etc. For example, most of the graduates who were hired by a company involved solely in the UAV business were the students who worked on UAV projects more than one academic year. The author has no knowledge of the company hiring the Cal Poly Pomona graduates prior to 2012 .

Also, many non-graduating students have been selected for internship opportunities at the companies and Government organizations including Northrop Grumman Corporation, The Boeing Company, General Atomics, and NASA to work in the areas of UAVs. The number of students getting summer internship positions has significantly increased. In the summer of 2015 alone, about 20 students worked as summer intern in the areas of UAVs.

It has been observed that those students who were part of the UAV projects for more than one year had more success in getting employment than the students who were worked in these projects as part of their Senior Project alone. It has also been observed that the students who presented and published their work at conferences had higher success rate in getting employment 
offers. Another noteworthy observation is that the students who have acquired skills via involvement in the UAV projects for an extended period of time are likely to get employed after gradaution even with low GPAs (GPA between 2 and 3).

\section{B. Development of New Skills and Knowledge}

These projects have been helpful for the students in developing new skills and knowledge in the disciplines other than their major. Students are exposed to the state-of-the-art in UAV technologies and industrial trends. The students get opportunity to learn other disciplines that are not taught in classroom settings of individual disciplines. For example, students from Aerospace Engineering major have learned or have opportunity to learn computer programming, computer vision, electronics, avionics system, communication system, etc. Similarly, the students in the Computer Science and Electrical \& Computer Engineering departments get opportunity to learn about the application of these disciplines to Aerospace Engineering and UAV technologies. The Aerospace Engineering students have learned these disciplines, and have successfully completed the projects, in some cases without resorting to any help from students in other departments. This is evidenced by the Aerospace Engineering students authoring or co-authoring and presenting papers on collision avoidance systems for UAVs, avionics systems, search and rescue using UAVs, and modeling and simulation at student and professional conferences ${ }^{3,4,5,10,11,14}$. This is also evidenced by a number of Aerospace Engineering majors getting employment for the industry careers that have traditionally required Computer Science or Electrical \& Electronics Engineering graduates such as in Jet Propulsion Laboratory, Unmanned Systems Division of Northrop Grumman Corporation, etc.

Increased emphasis is placed on interdisciplinary learning, and students are highly encouraged to learn other disciplines as the companies involved in UAV technologies are increasingly looking for graduates with knowledge and skills in multiple disciplines.

\section{Improved Written and Oral Communication Skills}

These projects have been helpful in improving the students' written and oral communication skills. As the goal of these projects is to prepare a strong workforce for the future needs of industry and academia in UAV technologies, the students have strongly been encouraged to present their work at student and professional conferences. The students have also been encouraged to publish their work in the conference proceedings. This is necessary and important as the lack of strong written and oral communications has been identified as deficiency in STEM education, resulting in poor success rate. Study has found that presenting and publishing at conferences significantly improves students' communication skills, both oral and written, as compared to the presentations and writing as part of the curriculum alone ${ }^{17,18}$.

The number of students attending and presenting at both the student and professional conferences has consistently increased over the years as can be seen in Figure 12. This academic year alone, seven aerospace engineering students or student teams presented their work during a student conference and seven students presented their work during a professional conference. Also, the students are required to document their work and prepare a report at the end of the project as with projects in any other area. 


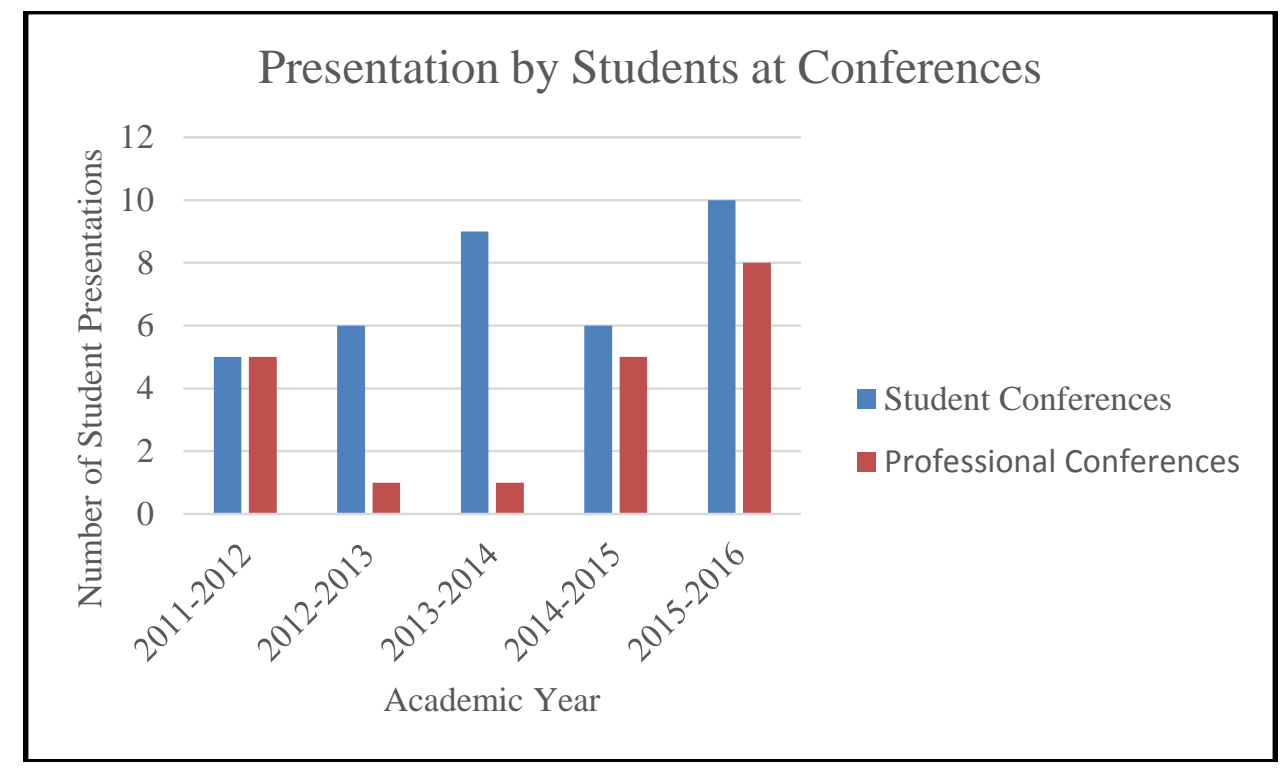

Figure 12: Number of Student Presentations at Conferences

Performance of students who were involved in the UAV related Senior Projects alone was compared to those who were involved in the UAV projects for more than one academic year. The presentations at student and professional conferences by the students involved in the Senior Projects alone in the past five year is insignficant. This cleary shows the effect of long term and sustained involvement in the UAV projects.

It has been observed that the students who have low GPAs, but have presented and published their work at conferences are more successful in getting employed than the students with no publication or presenations.

\section{Exposure to Multidisciplinary Environment}

The ongoing projects at Cal Poly Pomona on UAV technologies require multidisciplinary knowledge. Collaboration with students from other departments is emphasized and strongly encouraged as the aerospace industry is increasingly looking for graduates who have ability to work in multidisciplinary environment and who possess multidisciplinary knowledge and skills. For the successful completion of these projects, knowledge of Aerospace and Electrical \& Computer Engineering and Computer Science is important. The Aerospace Engineering students have shown increased ability to work in teams that involve students from other departments. Almost all the projects now involve students from Aerospace Engineering and one or more other departments. The students have shown desire to learn other disciplines and are aware of the importance of working in multidisciplinary teams. This is again evidenced by the Aerospace Engineering students getting employment for positions that traditionally require other disciplines as well as them authoring and presenting papers on topics that are not traditionally aerospace disciplines. The Aerospace Engineering students have also been able to communicate effectively to the students of other disciplines on the importance of their disciplines to the projects on UAV technologies. 


\section{E. Increased Motivation for Graduate Studies}

The students who worked or have been working on these projects are pursuing or have shown interest in pursuing their studies for graduate degrees, both at Master's and PhD levels. The number of students applying for graduate degrees has increased over the years. Figure 13 shows the number of students who were part of the UAV projects, and have pursued graduate degrees right after the graduation for the past five years. The projects have also taught the students to become lifelong learners. Participation and presentation during the student and professional conferences has also helped the students in developing lifelong learning skills and desire to pursue studies for graduate degrees. At least four students are pursuing or planning to pursue their studies for $\mathrm{PhD}$ degrees in the area of UAV technologies and related areas. This is as a result of the exposure to the area of UAV technologies and mentoring of the students for an extended period of time. Study has shown that participation in research projects motivates Undergraduate students for graduate degrees ${ }^{19}$. As stated above, the students involved in the $\mathrm{UAV}$ projects are working in a research environment even if they are working on their senior projects.

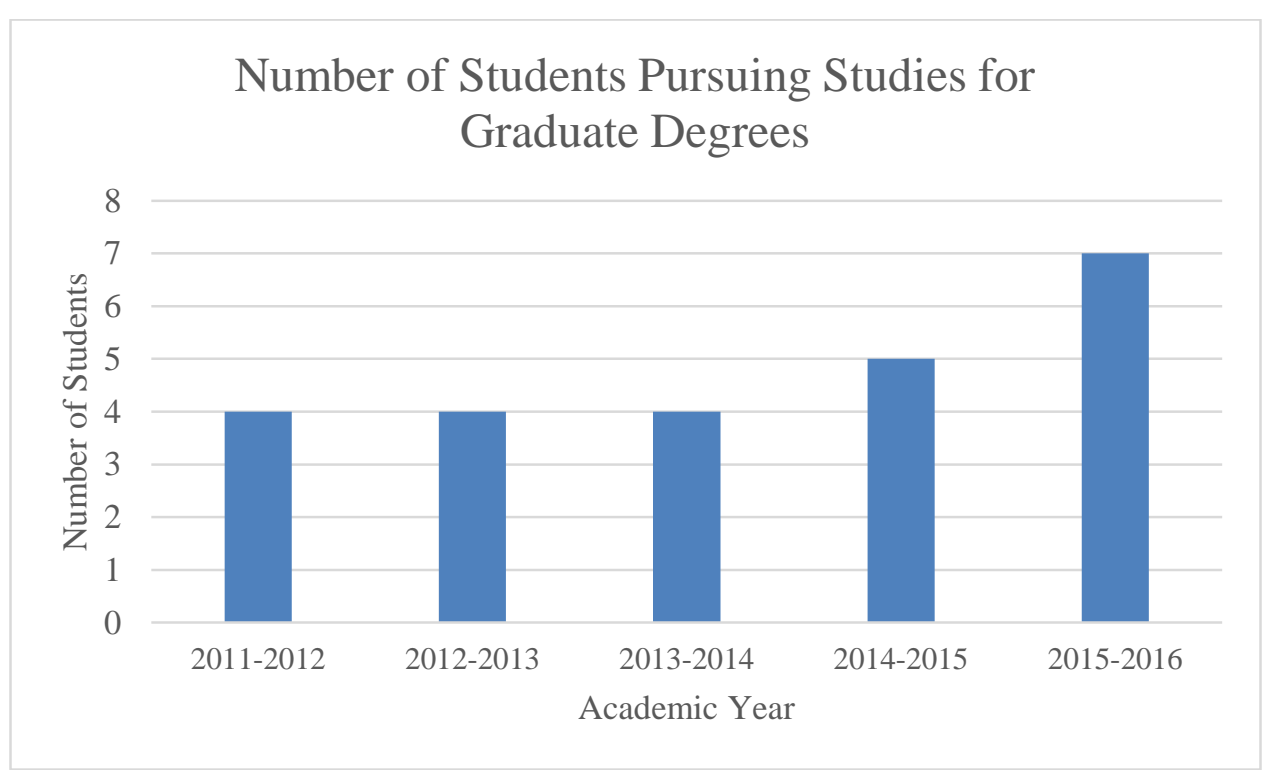

Figure 13: Number of Students Pursuing their Studies for Graduate Degrees

Again, comparing the motivation of the students who were involved in the Senior Projects alone to those who were involved for more than a year, the author has no knowledge of the graduates who were involved in the Senior Projects alone and are pursuing or plan to pursue their studies for a $\mathrm{PhD}$ degree. However, it is also found that a large number of graduates are pursuing or plan to pursue their studies for Master's degree regardless of the projects they are involved in.

\section{Conclusion}

Many Aerospace Engineering students are being involved in projects related to state-of-the-art UAV technologies. The students usually get exposure in these projects for an extended period time, usually throughout their undergraduate career at Cal Poly Pomona. The projects emulate the real-world problems typically exercised in the industry settings. The students get the 
opportunity to apply their knowledge to real-world problems. They design, build, perform system integration, simulate, and flight test the UAVs. The students get exposure to collecting, analyzing, and using flight data. The involvement in these projects have been found to be helpful in well preparing the students for industry and academia. Most of the students working on these projects have been immediately employed at the companies working in the area of UAV technologies and related areas. The students have also shown increased interest for graduate degrees.

The projects have also been found to be helpful for the Aerospace Engineering students in learning other disciplines, working in a multidisciplinary team environment, and improving oral and written communication skills via presentation and publication at student and professional conferences.

\section{Acknowledgement}

The author would like to thank Northrop Grumman Corporation, Boeing Company, Lockheed Martin Corporation, National Science Foundation, NASA Armstrong Flight Research Center/AERO Institute, California Space Grant Consortium, and various student support programs at Cal Poly Pomona for providing funding support for these projects.

\section{References}

1. Anon, http://tealgroup.com/index.php/about-teal-group-corporation/press-releases/94-2013-uav-press-release, Teal Group, 17 June 2013.

2. Anderson, N., Hagenauer, B., Erickson, R., and Bhandari, S., "Flight Testing of a UAV Airplane for Autonomous Operation using Piccolo II Autopilot," Proceedings of AIAA Atmospheric Flight Mechanics Conference, Honolulu, HI, 18-21 August 2008.

3. Richards, B. Gan, M., Bhandari, S., et al., "Collision Avoidance System for UAVs using Computer Vision," Proceedings of AIAA Infotech@Aerospace, Kissimmee, FL, January 5-9, 2015.

4. Wagster, J., Bhandari, S., et al., "Obstacle Avoidance System for a Quadrotor UAV," Proceedings of AIAA Infotech@Aerospace, Garden Grove, CA, June 19-21, 2012.

5. Gray, J., Wood, J., Piana, M., Bhandari, S., Tang, D., et al., "Collision Avoidance System for Unmanned Aerial Vehicles," Proceedings of the AUVSI Unmanned Systems 2015, Atlanta, GA, 4-7 May 2015.

6. Demonteverde, R., Cecil, T., Bhandari, S., Tang, D., Boskovich, S., Zekeriya, A., et al., "Collaboration between Multiple Unmanned Vehicles for Increased Mission Efficiency,"Proceedings of Infotech@Aerospace Conference, San Diego, CA, 4-8 Jan. 2016.

7. Bhandari, S., Rose, M., et al., "Tracking of Mobile Targets using UAVs," Proceedings of AIAA Guidance, Navigation, and Control Conference Invited Session, Minneapolis, MN, August 13-17, 2012.

8. Ding, K., Raheja, A., and Bhandari, S. "Application of Machine Learning for the Evaluation of Turfgrass Plots using Aerial Images," To Appear in the Proceedings of SPIE Autonomous Air and Ground Sensing Systems for Agricultural Optimization and Phenotyping Conference, Baltimore, MD, 17-19 April 2016.

9. Fechheimer, M., Webber, K., Kleiber, P. B., "How Well Do Undergraduate Research Programs Promote Engagement and Success of Students?," CBE Life Sciences Education, Sundberg, MD, 2011.

10. Bhandari, S., Pernalete, N., Bettadapura, A., Dadian, O., et al., "Avionics System for UAV Flight Controls Research,” Proceedings of AIAA Infotech@Aerospace, Boston, MA, August 19-22, 2013.

11. Bhandari, S., Bettadapura, A., Dadian, O., et al., "Search and Rescue using Unmanned Aerial Vehicles," Proceedings of AIAA Infotech@Aerospace, Kissimmee, FL, January 5-9, 2015. 
12. Martel, F., Schultz, R. R., et al., "Unmanned Aircraft Systems Sense and Avoid Avionics Utilizing ADS-B Transceiver," Proceedings of AIAA Infotech@Aerospace Conference, Seattle, WA, April 6-9, 2009.

13. Whalley, M., Theodore, C., Takahashi, M., et al., "Design and Flight Test Results for a Hemispherical LADAR Developed to Support Unmanned Rotorcraft Urban Operations Research," American Helicopter Society $64^{\text {th }}$ Annual Forum, Grapevine, TX, May 27-29, 2009.

14. Gomez, E., Garcia, D., Piana, M., Ritterbush, M., and Bhandari, S., "Simulation Enviroment for Testing UAS Collision Avoidance System," Proceedings of Infotech@Aerospace Conference, San Diego, CA, 4-8 Jan. 2016.

15. Koenig, S. and Likhachev, M., "Fast Replanning for Navigation in Unknown Terrain," Transactions on Robotics, 21(3), 2005.

16. Srinivasan, T., and Bhandari, S., "Path-Planning around Obstacles for a Quadrotor UAV Using the RRT Algorithm for Indoor Environments," Proceedings of Infotech@Aerospace Conference, San Diego, CA, 4-8 Jan. 2016.

17. Tapper, J. and Gruba, P., "Using a 'Conference Model' to Teach Communication Skills in a Communication Across the Curriculum Program," Language and Learning Across Disciplines, Vol. 4, No. 1, May 2000.

18. Borstler, J. and Johansson, O., "The Student Conference - a Tool for the Teaching of Research, Writing, and Presentation Skills, SIGCSE Bulletin, Vol 30, No. 3, pp. 28-31, 1998.

19. N. Dukhan and M. Jenkins, "Undergraduate Research as a Motivation for Attending Graduate School," Proceedings of ASEE Annual Conference, Honolulu, HI, 24-27 June 2007. 